\author{
FINAL REPORT \\ U.S. Department of Energy
}

\title{
CHEMICAL DECOMPOSITION OF HIGH-LEVEL NUCLEAR WASTE STORAGE/DISPOSAL GLASSES UNDER IRRADIATION
}

\author{
Principal Investigator: David L. Griscom \\ Co-Investigator: Celia I. Merzbacher \\ Optical Sciences Division \\ Naval Research Laboratory \\ Washington, DC 20375
}

Project Number: 55188

Grant Number: DE-AI07-96ER45619

Grant Project Officers: Helen Farrell and Gordon Roesler

Project Duration: November 1996-December 1999 


\section{TABLE OF CONTENTS}

EXECUTIVE SUMMARY

RESEARCH OBJECTIVES

RESEARCH METHODS AND RESULTS ………………........................... 7

Experimental Methods.........................................................................

Defense Waste Processing Facility Glasses.................................................

Iron Phosphate Glasses............................................................................

An Iron-Free Model High-Level Waste Glass......................................... 11

Geological Glasses........................................................................

Model HLW Glass Simulants from Pacific Northwest National Lab....... 14

${ }^{238} \mathrm{Pu}$-Containing Glasses................................................................... 14

Post Script: A Possible Lesson from Geological Glasses.......................... 16

TECHNICAL SUMMARY..........................................................................

RELEVANCE, IMPACT AND TEĊHNOLOGY TRANSFER ........................... 17

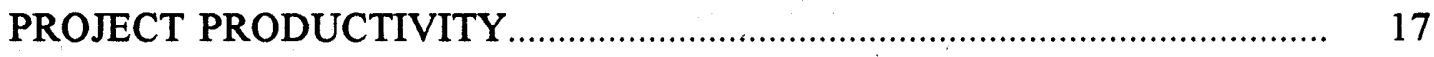

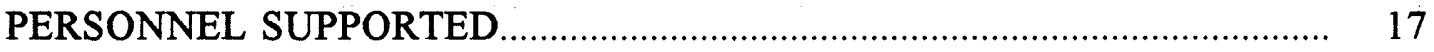

PUBLICATIONS

INTERACTIONS

PATENTS

FUTURE WORK

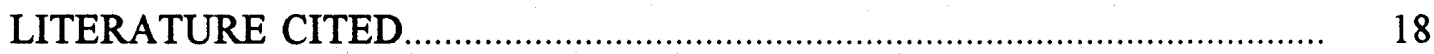




\section{EXECUTIVE SUMMARY}

The-object of this research has been to use the technique of electron spin resonance (ESR) to discern evidence for chemical decomposition of glasses employed or contemplated for use as media for storage/disposal of high-level nuclear wastes (HLW) or excess weapons plutonium. ESR measures the absorption of fixed-frequency microwaves by the magnetic moments of unpaired electrons as a function of the strength of an externally applied magnetic field. Except for certain transition-group ions (such as trivalent iron) most atoms in insulating materials find all of their electrons to be in pairs an hence not contributing to the ESR spectrum. Nuclear radiations disrupt this situation by dislodging electrons from their normal locations (leaving behind electron "holes") and trapping them in other locations. The electron and hole trapping sites are referred to as "color centers" because their presence can turn a clear material into a darkened one, with the specific tint depending on the chemical nature(s) of the trapping site(s). Some forms of radiation, such as $\alpha$ particles, $\beta$ particles and $\gamma$ rays, are capable of displacing whole atoms or ions from their normal locations and depositing them into interstitial spaces. When an unpaired electron or hole traps on one of these vacancies or interstitials, it too becomes a color center. Among the advantages of ESR are its abilities to detect the very earliest stages of radiolytic decomposition and to determine unambiguously the types and numbers-even at levels of parts per million (ppm)-of the "color centers" induced in irradiated insulating materials, including glasses.

For several decades evidence has been reported in the literature for the presence oxygen-gas bubbles gas in various silicate glasses as a consequence of exposure to nuclear radiations. Although it is universally agreed that bubbles form when samples are studied by electron microscopy (which irradiates the material with $\beta$ particles in order to image it), some controversy had arisen regarding whether any of these bubbles occur in consequence of prior irradiations. Therefore, one of the specific objectives of this project has been to look for color centers consisting wholly or in part of superoxide ions $\left(\mathrm{O}_{2}{ }^{\circ}\right)$, since these are easily seen and recognized by ESR and they comprise chemical intermediates in reactions leading to oxygen molecule formation (i.e., $2 \mathrm{O}_{2}^{-} \rightarrow \mathrm{O}_{2}{ }^{2-}+\mathrm{O}_{2}$ ). The search for superoxide ions, or the related peroxy 
radicals $\left(\mathrm{RO}_{2}^{-}\right)$, was successful in model $\mathrm{HLW}$ glasses not containing significant amounts of iron oxide. In one case, separate samples of an iron-free boro-aluminosilicate model HLW glass were separately exposed to $1.2 \mathrm{MeV} \gamma$ rays and implantation by $160-\mathrm{keV} \mathrm{He}^{+}$ions (low-energy $\alpha$ particles) to approximately equivalent doses of deposited energy. Color centers comprising holes trapped on oxygens next to boron ions (BOHCs) and electrons trapped on titanium ions were observed in the $\gamma$-irradiated samples at levels of $30 \mathrm{ppm}$ and $5 \mathrm{ppm}$, respectively. Upon heating to $300{ }^{\circ} \mathrm{C}$, the BOHCs and $\mathrm{Ti}^{3+}$ centers disappeared, revealing an underlying signal due to peroxy radicals at a level of about $1 \mathrm{ppm}$. By contrast the He-implanted samples showed no BOHCs or $\mathrm{Ti}^{3+}$ color centers but revealed peroxy radical concentrations 100 times greater than in the $\gamma$ irradiated sample on a per-unit-dose basis. Explanations for the dependance on type of radiation are offered in the full report. It is concluded that this particular glass would probably develop oxygen bubbles-under irradiation, particularly by $\alpha$ particles.

A related concern has been that if oxygen molecules are released, some of the metal ions in the glass must undergo chemical reduction. Since the iron-free glass investigated here contained $18 \mathrm{wt} \%$ sodium oxide, the possibility of sodium metal colloid formation was considered. An ESR signal considered as possibly due to colloidal sodium in the He-implanted glass was studied in detail and found not to be due to sodium; rather, it was shown to arise from a carbon impurity on the sample surface acquired during implantation. Thus, no evidence was found to support the specter of radiation-induced precipitation of metallic sodium - capable of catching fire and burning in a flame fed by the oxygen accumulated in the bubbles. These glasses may therefore be safe for long-term storage of high-level wastes notwithstanding the likelihood of some bubble formation.

A number of glasses containing five or more weight $\%$ of iron oxide were also studied, including Defense Waste Processing Facility (DWPF) glasses from the Savannah River Technology Center (SRTC) and model HLW glasses from Pacific Northwest National Laboratory (PNNL), which had been exposed to $\gamma$-ray doses up to the equivalent to 25 years storage of $\mathrm{HLW}$ radionuclides such as ${ }^{137} \mathrm{Cs}$ and ${ }^{90} \mathrm{Sr}$. In all of these cases, no induced color centers were observed by ESR, and changes in iron valence state, 
if any, were not measurable by ESR within the currently achievable precision of $\pm 5 \%$. It is concluded that iron oxides in amounts of $5 \mathrm{wt} \%$ or greater exert a suppressive effect on color center formation. It is cautioned, however, that failure to detect induced superoxide species does not preclude direct formation of interstitial $\mathrm{O}_{2}$. Fortunately, within the past two years, new methods for unambiguous detection of interstitial oxygen molecules in transparent solids have been developed by others, and these types of measurements (see cited literature refs. [32] and [33]) are therefore recommended as a means to finally settle the question of whether or not the often reported bubble formation can be due to interstitial $\mathrm{O}_{2}$ molecules induced by $\gamma$ and $\beta$ irradiations.

During the first year of the project, a major effort was devoted to studies of the structure and radiation sensitivity of high-iron phosphate glasses. Several lines of evidence initially convinced the Principal Investigator that these glasses contained superoxide ions in their as prepared states. However, additional evidence gathered by the Principal Investigator and his informal collaborators at the University of Missouri-Rolla (project 55110), Toyo University (Japan), and University of Reading (UK) reversed this notion. In general, the high-iron phosphate glasses have displayed high chemical durability, and the neutron diffraction studies performed at Reading point to the reason why, namely, that the phosphorus and iron ions may tend to form a silica-like network of $\mathrm{PO}_{4}$ and $\mathrm{FeO}_{4}$ tetrahedra joined at the corners. The only ESR-observed radiation effects in seven studied high-iron phosphate glasses were in a glass fabricated and irradiated at SRTC. Because this sample was a fine powder and was irradiated in air, while all other samples were either monolithic or irradiated in vacuo, it is tentatively concluded that the superoxide signal in the former case was due to radiation stimulated reaction of the high surface area sample with atmospheric oxygen. From the Principal Investigator's experience in this project, high-iron phosphate glasses should provide the ideal means for vitrification of certain phosphate-rich tank wastes on the Hanford reservation.

Toward the end of the final year of the contract, a set of three model plutonium glasses developed at Pacific Northwest National Laboratory (project 54672) were shipped to NRL at the request of the 
Principal Investigator. These Defense Waste Reference Glasses were high-iron (10 weight $\% \mathrm{Fe}_{2} \mathrm{O}_{3}$ ) boroaluminosilicate glasses fabricated 17 years ago to contain $1.0 \mathrm{wt} \% \mathrm{PuO}_{2}$, with various substitutions of ${ }^{238} \mathrm{Pu}$ in place of the weapons isotope, ${ }^{239} \mathrm{Pu}$. The glass (DRG-P3) containing the highest amount of ${ }^{238} \mathrm{Pu}$ (half life 87.7 years) emulated the combined effects of $5.2-\mathrm{MeV} \alpha$-particle and $86 \mathrm{keV} \alpha$-recoil damage which would accumulate in an actual ${ }^{239} \mathrm{Pu}$-containing glass after 4,700 years of storage. Again, no color center formation was noted by ESR (although it is again cautioned that the presence of interstitial $\mathrm{O}_{2}$ cannot be discounted on this basis). However, for the first time, a profound ESR-detectable effect was recorded. Namely, a part of the spectrum attributable to $\mathrm{Fe}^{3+}$-ion clusters was reduced in strength in the DRG-P3 glass by about $50 \%$ relative to the glass containing only ${ }^{239} \mathrm{PuO}_{2}$. Concomitantly, the ESR signal of isolated $\mathrm{Fe}^{3+}$ ions was approximately doubled. Since it was found at PNNL that the DRG-P glasses were slightly inhomogeneous in their as-prepared conditions, the ESR results show that the $\alpha$-decayinduced atomic displacements, combined with the high-temperature remelting of the glass in the thermal spikes surrounding the $\alpha$-particle and $\alpha$-recoil-ion tracks, has begun to homogenize the glass on a fine scale. In principal, this homogenization could make the glass more resistant to ground water attack than it was in its as-prepared condition, since in phase-separated glasses the least chemically durable phase generally determines the environmental viability of the whole.

Some 65 -million-old geologic tektite glasses containing $5 \mathrm{wt} \%$ iron oxide were also studied for evidence of $\alpha$-decay damage due to naturally occurring ${ }^{238} \mathrm{U}$ and ${ }^{232} \mathrm{Th}$. In light of the non-observation of color centers in the aforementioned ${ }^{238} \mathrm{Pu}$ glasses, the color centers observed in the tektites are deemed likely to be associated with a minor component comprising nearly pure silica glass. However, the evident immunity of these 65 -million-year-old glasses to water attack encourages further research to determine if vitreous waste forms mimicking natural glasses can be developed with such high chemical durabilities as to promise to outlive their geologic repositories. 


\section{RESEARCH OBJECTIVES}

In the United States alone there are 100 million gallons of high-level nuclear wastes (HLWs) in various chemical forms awaiting eventual disposal in geologic repositories [1]. For safety in handling and transport from their present underground storage tanks to their final burial sites, much of the HLWs are being immobilized by vitrification [1-3]. A further virtue of HLW vitrification is the fact that the glass may serve as an additional, non-geologic barrier to the dispersal of these radio-toxins into the environment. For this reason, one of the criteria for selecting HLW glass compositions has been chemical durability against attack by ground water. While the effects of radiation on chemical durability have therefore been studied extensively $[1,4,5]$, little consideration has been given to the possibility that self-irradiation of HLW glasses may lead to modes of chemical decomposition which render them unstable even in the absence of exposure to ground water. The worst-case threat would occur if the HLW glasses were to respond to irradiation in ways analogous to rock salt $(\mathrm{NaCl})$. It has long been known that alkali halides irradiated to sufficiently high doses decompose into alkali-metal colloids and interstitial halogen molecules $[6,7]$. However, more recently it has been discovered that some rock salts also develop voids under high-dose irradiation [8] and that heating of these materials in the range $\sim 200^{\circ} \mathrm{C}$ can cause these voids to collapse, triggering shock waves capable of detonating explosive recombination of the radiolytically accumulated elemental sodium and chlorine molecules [9]. (These results should serve as a precautionary tale, particularly with regard to the current practice of immobilizing radioactive ${ }^{137} \mathrm{Cs}$ as $\mathrm{CsCl}$ !)

Therefore, the objective of this project was to employ the technique of electron spin resonance (ESR), in conjunction with other experimental methods, to study radiation-induced decomposition of vitreous compositions proposed for immobilization/disposal of high-level nuclear wastes (HLW) or excess weapons plutonium. ESR is capable of identifying, even at the parts-per-million level, displaced atoms, ruptured bonds, and free radicals created by radiation in such glassy forms. For example, one of the principal scientific goals was to search for ESR-detectable superoxide $\left(\mathrm{O}_{2}\right)$ and ozonide $\left(\mathrm{O}_{3}\right)$ ions, which could be precursors of radiation-induced oxygen gas bubbles reported by other investigators [10]. Whenever superoxide ions are present in a material, oxygen molecules (though "invisible" to ESR) can be inferred to be present because of the tenancy of superoxides to disproportionate [11]: $2 \mathrm{O}_{2}^{-}=\mathrm{O}_{2}{ }^{2-}+\mathrm{O}_{2}$. The fundamental understandings obtained in this study were intended to enable reliable predictions of the long-term effects of $\alpha$ and $\beta$ decays of the immobilized radionuclides on the chemical integrity of HLW glasses.

\section{RESEARCH METHODS AND RESULTS}

This report summarizes the final results of an effort performed under a 3-year research award. Six groups of materials were studied: (A) several actual and proposed HLW glass compositions fabricated at Savannah River Technology Center (SRTC), (B) several high-iron phosphate glasses fabricated at the University of Missouri-Rolla (UMR), (C) an iron-free boroaluminosilicate model HLW glass subjected to $\gamma$ rays (to simulate $\beta$-decay effects) and to implantation by $160-\mathrm{keV} \mathrm{He}^{+}$ions (to simulate $\alpha$-decay damage), (D) well-dated geological glasses damaged by $\alpha$ decays of trace amounts of contained ${ }^{238} \mathrm{U}$ and ${ }^{232} \mathrm{Th}$ over a period of 65 million years, (E) a series of HLW model glasses prepared at Pacific Northwest National Laboratory (PNNL) and $\gamma$-irradiated at various temperatures, and (F) three compositionally identical defense reference glasses (DRG) prepared at PNNL in 1982 to have ${ }^{238} \mathrm{Pu} /{ }^{239} \mathrm{Pu}$ ratios of $0,0.11$, and 9 . The ${ }^{238} \mathrm{Pu} \alpha$-decay damage sustained by these 17 -year-old samples is equivalent to the effect storing an equivalent amount of vitrified ${ }^{239} \mathrm{Pu}$ for $\sim 4,700$ years.

Much of the research carried out under this grant has been described in depth in two published papers $[12,13]$ which are only briefly summarized and updated below. These works should be consulted for further details. The remainder of this report describes additional studies which have not been published, including investigations of the ${ }^{238} \mathrm{Pu}$-containing glasses which are expected to result in an additional publication at a later date [14].

\section{Experimental Methods}

The main experimental technique employed was electron spin resonance (ESR). Standard continuouswave ESR spectrometers record the absorption of fixedfrequency microwaves as a function of the magnitude, $H$, of an externally applied static magnetic field, $\mathbf{H}$. Conventionally, a small-amplitude modulation is superimposed on $\mathbf{H}$ and phase-sensitive detection is employed, so that the recorded signal generally consists of the first derivative of the absorption curve. Only unpaired electrons contribute to ESR, since the method stimulates transitions between the quantummechanically discrete energy levels of the electron magnetic moment, which is proportional to the quantum-mechanical spin, $S$. An individual electron has spin $S=1 / 2$, whereas paired electrons have $S=0$. Therefore, the measurable species include only certain transition-group ions (e.g., $\mathrm{Fe}^{3+}$ ), point defects ("color 
centers") induced by irradiation which trap individual electrons or holes, and ferro- or ferri-magnetic particles precipitated in glasses (principally $\mathrm{Fe}^{0}$ or magnetite). The positions of the ESR lines can be understood theoretically in terms of "spin-Hamiltonians", $\mathcal{H}$, which parameterize all of the measurable interactions of the unpaired spin with its surroundings [15]. In particular, the $g$ value is defined by $h v=g \beta H$, where $h$ is Planck's constant, $v$ is the spectrometer frequency and $\beta$ is the Bohr magneton. An introduction to ESR in glasses is provided in ref. [16]. The number density of the ESRactive species is determined by integrating the areas under the absorption curves and making comparison to the similarly recorded and integrated intensity of a calibrated standard sample. Theoretical corrections [17] are required when the spin $S$ of a paramagnetic experimental species differs from that of the standard (e.g., $S=5 / 2$ for $\mathrm{Fe}^{3+}$, while $S=1 / 2$ for the presently employed Varian "strong pitch" standard sample). Corrections can also be made for cases where the experimental species comprise ferromagnetic particles, provided the mineralogical natures of these particles are known and their sizes can be determined [17].

\section{DWPF Glasses}

Among materials of group A were two samples of Defense Waste Processing Facility (DWPF) borosilicate glasses modeling compositions currently being used to vitrify HLW at SRTC. The ESR spectra recorded for the unirradiated DWPF-glass simulants (Fig. $1(f)$ and (g)) were attributable to $\mathrm{Fe}^{3+}$ ions and/or precipitated ferrimagnetic phases (ferrites). The sole potentially ESR-measurable effect of a 30-MGy $\gamma$ irradiation (1 $\mathrm{Gy}=100 \mathrm{rad})$ was induced changes in the $\mathrm{Fe}^{3+}$ concentrations, since no induced changes in the ESR line shape could be discerned. Accordingly, eight ESR spectra were recorded for each of six carefully weighed samples, three of which were irradiated and three not. The result was an apparent radiation-induced reduction of the $\mathrm{Fe}^{3+}$ signals in the irradiated samples by a factor $0.987 \pm 0.050$ relative to the unirradiated ones [12]. Not only is this figure statistically insignificant, but it appeared to contain systematic errors owing to uncontrollable differences in the packing factors of the powder-form samples.

In addition to there being no measurable iron-ion valence changes, no induced defect centers (possessing ESR line shapes distinctively different from those of $\mathrm{Fe}^{3+}$ ) were detected by ESR, possibly due to a suppression effect of the contained iron ions (see below). In this context, it should be noted that the presence or absence of radiolytic $\mathrm{O}_{2}$ cannot be directly determined by ESR. Thus, the presence of interstitial oxygen molecules is not disproved by the present negative experiment.

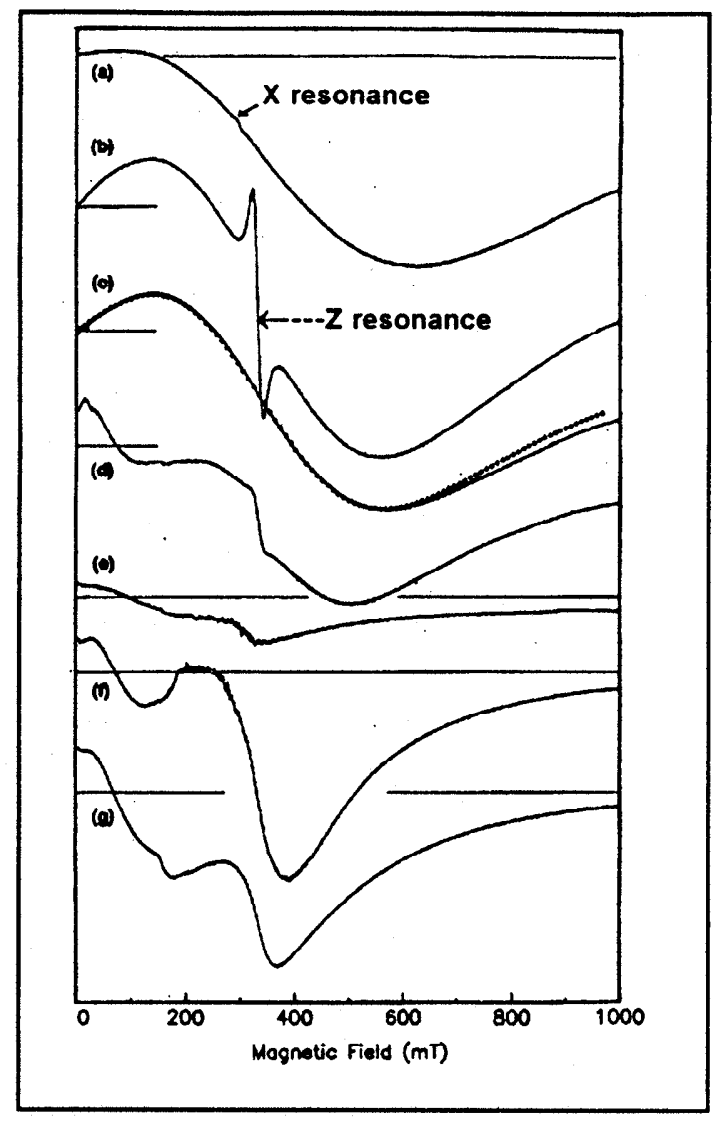

Figure 1. ESR spectra of some unirradiated HLW glass simulants, including four high-iron phosphate glasses: (a) FCsSr3, (b) $\mathrm{PO}_{4}^{-3}$, (c) $\mathrm{F} 27$, and (d) C-112. Also shown: lanthanum-silicate composition (e) LAB and ( $f$ and $g$ ) two DWPF glasses.

\section{Iron Phosphate Glasses}

Another group-A material, a high-iron phosphate glass containing $\mathrm{Li}_{2} \mathrm{O}$ and $\mathrm{CeO}_{2}$, displayed a rather large $\gamma$-ray-induced ESR response, in contrast with the radiation immunity of the DWPF glass (so far as ESRdetectable damage is concerned). Specifically, an ESR signal identified as likely arising from $\sim 2 \times 10^{18}$ radiolytic superoxide ions $\left(\mathrm{O}_{2}\right)$ ions per gram was recorded for a sample of the high-iron phosphate glass (denoted " $\mathrm{PO}_{4}-3$ " in Table 1) which had been irradiated at SRTC to a dose of $30 \mathrm{MGy}$ at [12]. This signal was not present in a replicate sample which was not irradiated. However, after ref. [12] had gone to press, a portion of the replicate sample of the $\mathrm{PO}_{4}-3$ glass, as well as samples of several other high-iron phosphate glasses listed in Table 1, were irradiated at the Naval Research Laboratory (NRL) to ${ }^{60} \mathrm{Co} \gamma$-ray doses ranging from 10 $\mathrm{kGy}$ to $10 \mathrm{MGy}$ without any observed effect on the ESR spectra of any of these samples. The ambient conditions during the irradiations were similar 
(temperatures $\sim 25 \mathrm{C}$ in each case and all samples were powders). However, the experimental conditions differed in one potentially significant way, namely, the SRTC samples were irradiated and stored in air while the NRL samples were irradiated and subsequently stored in evacuated, sealed fused quartz tubes. It seems well within the realm of possibility that atmospheric $\mathrm{O}_{2}$ molecules react with radiation-induced trapped electrons on or just below the surfaces of the irradiated glasses to form the $\mathrm{O}_{2}{ }^{-}$ions observed in the high-iron phosphate glasses (but not the borosilicate glasses) irradiated in air. This hypothesis needs to be tested further in order to avert any future confusion.

However, it seems highly doubtful that radiationactivated oxygen take-up by finely powdered glasses can be extrapolated to any serious problems for longterm immobilization of high-level nuclear wastes or weapons plutonium in monolithic high-iron phosphate glass "logs." Nevertheless, as described below, ESR observation of what still appears to be $\mathrm{O}_{2}^{-}$(superoxide) ions in the high-iron phosphate glass powders irradiated in air became an important part of a web of evidence extensively developed in ref. [12] for the possible presence of superoxide ions in the as-prepared highiron phosphate glasses. If it turns out that this oxygen was in fact adsorbed on the surfaces of the powder grains, then this part of the argument for superoxide in the bulk glasses is invalidated.

Table 1. Compositions in mole percent of some SRTC and UMR HLW glass simulants investigated in this study.

$\begin{array}{llllllll}\text { Sample } \mathrm{Fe}_{2} \mathrm{O}_{3} & \mathrm{P}_{2} \mathrm{O}_{5} & \mathrm{SiO}_{2} & \mathrm{~B}_{2} \mathrm{O}_{3} & \mathrm{Li}_{2} \mathrm{O} & \mathrm{CeO}_{2} & \text { Other }\end{array}$

\begin{tabular}{lrrrrrrr}
\hline DWPF & 4.8 & & 56.5 & 6.1 & 12.8 & & a \\
LAB & & & 55.2 & 10.5 & & 5.7 & b \\
PO $_{4}-3$ & 20.5 & 49.3 & & & 23.5 & 6.7 & \\
F27 & 25.0 & 75.0 & & & & & \\
F32 & 29.0 & 71.0 & & & & & \\
F43 & 40.0 & 60.0 & & & & & \\
$\mathrm{FCsSr3}$ & 28.0 & 47.0 & & & & & c \\
C-112 & 7.5 & 40.0 & 3.0 & & & & d
\end{tabular}

${ }^{\mathrm{a}} 10.4 \mathrm{Na}_{2} \mathrm{O}, 2.5 \mathrm{Al}_{2} \mathrm{O}_{3}, 2.6 \mathrm{MnO}, 1.7 \mathrm{CaO}, 1.3 \mathrm{MgO}, 0.75$ $\mathrm{NiO}, 0.63 \mathrm{ZrO}_{2}$

b. $\mathrm{La}_{2} \mathrm{O}_{3}, 7.2 \mathrm{PbO}, 4.1 \mathrm{Nd}_{2} \mathrm{O}_{3}, 7.2 \mathrm{Al}_{2} \mathrm{O}_{3}, 1.8 \mathrm{BaO}$

$9.0 \mathrm{CsCl}, 16.0 \mathrm{SrF}_{2}$

d.0 $\mathrm{Al}_{2} \mathrm{O}_{3}, 20.7 \mathrm{CaO}, 9.1 \mathrm{NiO}, 8.3 \mathrm{Na}_{2} \mathrm{O}, 8.1 \mathrm{U}_{2} \mathrm{O}, 0.4$ $\mathrm{PbO}$

Since high-iron phosphate glasses in general (composition range $\sim 0.2<[\mathrm{Fe}] /[\mathrm{P}]<0.67$ ) have displayed many properties favorable for vitrification of phosphate-rich high-level wastes such as are present at the Hanford site [18], the first 15 months of the present project were devoted to fundamental studies of $(A)$ the
SRTC lithium-cerium-iron-phosphate and (B) various UMR high-iron-phosphate glasses, including some samples specially melted to test a superoxide-Table 1 Batch compositions of the investigated glasses in mole percent. The $\mathrm{Fe}$ (II) fractions of some of these compositions determined by Mössbauer are reported in ref. [12].constituent model developed by the present investigators at the Naval Research Laboratory (NRL). As reported in paper [12], ESR, Mössbauer, thermal analysis, and quadrupole-mass-spectroscopic gasevolution studies were carried out in informal collaboration with the UMR and Toyo University (Japan). The ESR results at NRL have revealed the unirradiated glasses to possess unusual magnetic structure, which is qualitatively different that of the crystallized materials. Specifically, the extremely broad "X resonance" of Fig. 1 was found to convert essentially one-for-one into the narrow " $Z$ resonance" upon crystallization (see Fig. 2).

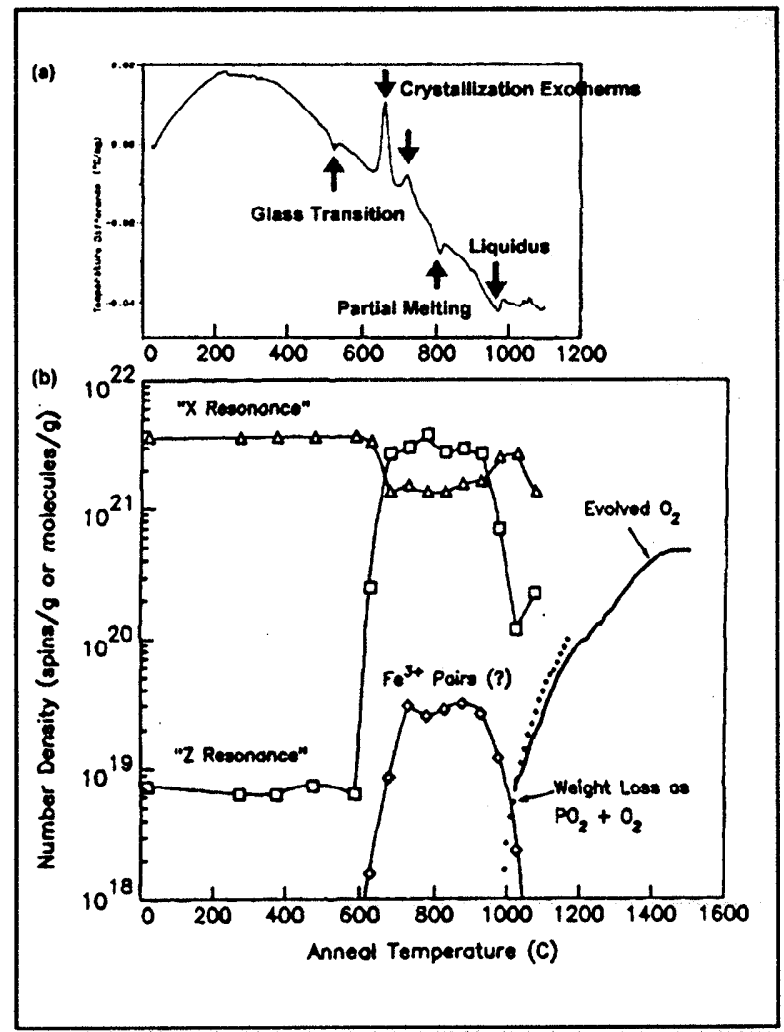

Figure 2. (a) Temperature difference during ramped heating and (b) ESR intensities after 10-min isochronal anneals (data points) for $\gamma$-irradiated iron phosphate glass $\mathrm{PO}_{4}-3$, with comparison to $\mathrm{O}_{2}$ gas evolution (bold curve) and TGA weight loss data (dots) for an unirradiated sample. ESR data for an unirradiated sample were similar to those of (b) except for the absence of the signal tentatively ascribed to $\mathrm{Fe}^{3+}$ ion pairs (diamonds). 


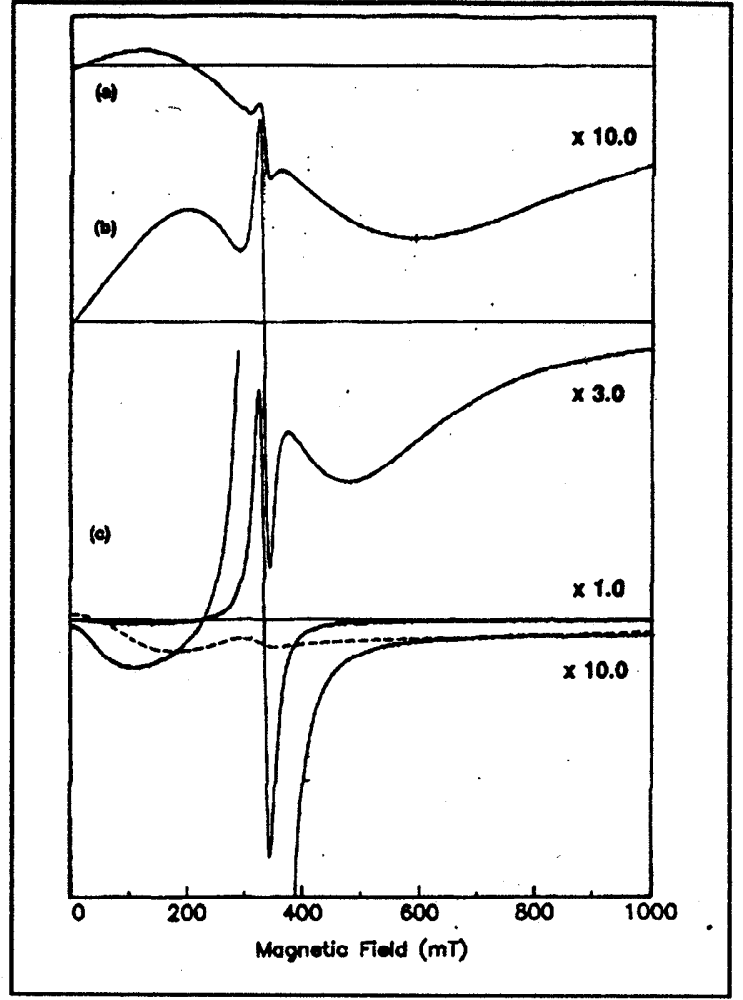

Figure 3. ESR spectra of identically batched binary iron phosphate glasses (composition F43) melted near $1200^{\circ} \mathrm{C}$ (fully drawn curves) under (a) air, (b) bubbled $\mathrm{O}_{2}$, and (c) $89 \% \mathrm{~N}_{2}, 9 \% \mathrm{H}_{2}, 2 \% \mathrm{O}_{2}$. Morssbauer measurements have shown $\left[\mathrm{Fe}^{2+}\right] /[\mathrm{Fe}]_{\text {total }}=0.19,0.21$, and 0.40 for the glasses of (a), (b), and (c), respectively. The dashed curve pertains to an F43 glass melted at $1450{ }^{\circ} \mathrm{C}$ and recorded at $20 \mathrm{X}$ ESR gain; the $\mathrm{Fe}^{2+}$ fraction was 0.57 for this glass.

The origins of the $X$ and $Y$ resonances had to be treated as unknown at the outset, since their measurable ESR characteristics do not unambiguously identify them. In principle, these signals could arise from the large amounts of $\mathrm{Fe}^{3+}$ in these glasses. However, the only known precedent for the $\mathrm{X}$ resonance was an occurrence in certain amorphous peroxyborate materials containing no iron oxides but shown to contain superoxide ions. The $\mathrm{X}$ resonance has certain well defined features, such as its broad Lorentzian line shape (dotted simulation in Fig. 1(c)) and the temperature dependence of the peak-to-peak linewidth, which follows a $T^{-x}$ law where $x<1$. These findings, in conjunction with the radiation effect mentioned above, led to the hypothesis that superoxide ions may somehow have become incorporated into the asprepared glasses iron phosphate glasses. Very specific models of glass structure were proposed which would, if correct, account for the occurrence of the $\mathrm{X}$ resonance in both the iron-free amorphous peroxyborates and the high-iron phosphate glasses of the present study. Initially, the gas-evolution studies at Toyo University (see "evolved $\mathrm{O}_{2}$ " in Fig. 2) seemed to support this hypothesis. However, as paper [12] was going to press, new gas evolution studies were carried out on a series of binary iron phosphate glasses melted under differing redox conditions, including a reduced glass exhibiting very little $\mathrm{X}$ resonance. As described in a note added in proof [12], all three of these glasses exhibited virtually the same qualitative and quantitative evolution of $\mathrm{O}_{2}$ gas, thus falsifying one of the principal predictions of the superoxide model.

The present investigators brokered a collaboration between the UMR group and Prof. A.C. Wright at the University of Reading (UK) to carry out polarizedneutron-diffraction study of the high-iron phosphate glasses to better elucidate the chemistry, topology, and magnetic structure of the glass network. This involves the measurement of both atomic and magnetic real space correlation functions. Prof. Wright measured the onset of magnetic ordering in a $44 \mathrm{~mol} \% \mathrm{Fe}_{2} \mathrm{O}_{3}-60$ mol\% $\mathrm{P}_{2} \mathrm{O}_{5}$ glass as a smooth, continuous growth of a peak at $Q \approx 0.8 \AA^{-1}$ from $\sim 100 \mathrm{~K}$ to $2.1 \mathrm{~K}$, there being no evidence for a sharp magnetic ordering transition, contrary to the results of Egami et al. [19]. He obtained the magnetic diffraction pattern by subtracting the pattern at $78 \mathrm{~K}$ from that at $2.1 \mathrm{~K}$, which was then Fourier transformed to yield the real space magnetic correlation function, $D^{\mathrm{M}}(r)$. The first real peak of $D^{M}(r)$ was found to be negative, thus indicating the antiferromagnetic nature of the short range magnetic ordering (i.e., speromagnetism) [20]. The position of this peak at $r=6.0 \AA$ represents the spatial separation of the antiferromagnetically-coupled magnetic species responsible for the speromagnetism. This distance is greater than prediction of the superoxide model proposed in [12] $(\sim 3 \AA)$ but is very close to the $\mathrm{Fe}^{3+}$. $\mathrm{Fe}^{3+}$ distance in the $\alpha$-quartz form of $\mathrm{FePO}_{4}$. This finding provides support for a model of $\mathrm{Fe}_{2} \mathrm{O}_{3}-\mathrm{P}_{2} \mathrm{O}_{5}$ glasses previously proposed [20], namely, a silica-like network of alternating, corner-sharing $\mathrm{FeO}_{4}$ and $\mathrm{PO}_{4}$ tetrahedra, supplemented by the excess $\mathrm{P}_{2} \mathrm{O}_{5}$ in the form of $\mathrm{O}=\mathrm{PO}_{3}$ units sharing only three corners. This model differs from one developed at UMR based on neutron and $x$-ray diffraction studies of the crystallized materials, which involves both $\mathrm{Fe}^{3+}$ and $\mathrm{Fe}^{2+}$ ions [21]. An important question, therefore, concerns the fraction of the $\mathrm{Fe}$ which is present as $\mathrm{Fe}^{2+}$, the nature of the $\mathrm{Fe}^{2+} \mathrm{O}_{\mathrm{n}}$ polyhedra, and the role these polyhedra play in forming, or modifying, the vitreous network. Whichever model is correct, the magnetic neutron scattering results provide additional reason for abandoning the NRL model of an iron-phosphate glass structure incorporating superoxide ions. 
Further neutron diffraction work is in progress and will be published on completion of the experiments and further analyses [22]. Prof. Wright has also submitted a proposal to investigate the growth of the magnetic small angle neutron scattering (SANS) that accompanies the development of the spatial magnetic correlations, as the temperature is reduced from $\sim 100$ to $2 \mathrm{~K}$. This study will give information concerning the temperature dependence of the magnetic correlation length and hence the degree of magnetic anisotropy in the system.

Leaving aside present controversies regarding the precise atomic-scale structures of iron phosphate glasses (which should soon be resolved by neutron diffraction), the present study has shown the ESR " $\mathrm{X}$ resonance" to be an easily recorded finger print of speromagnetic (short-range antiferromagnetic) coupling in glasses and the " $Z$ resonance" to be a marker of an entirely different magnetic behavior, presumably longer-range antiferromagnetism such as is expected for crystals. (Note that the data of Fig. 2(b) show the $\mathrm{Z}$ resonance to supplant the $\mathrm{X}$ resonance when the $\mathrm{PO}_{4}-3$ glass crystallizes and vice versa when the crystals remelt.) Furthermore, the present work has shown that the magnetic structure of a high-iron phosphate glass contemplated for disposal of waste plutonium $\left(\mathrm{PO}_{4}-3\right)$ is sensitive to the amount of water in the batch materials [12], the melting temperature, and the melting atmosphere for a given temperature (see Fig. 3).

Whereas neutron diffraction experiments must be performed at one of the few high-intensity sources of monochromatic neutrons available in the world and beam time must be scheduled months in advance, ESR spectra can be run in a matter of minutes on a standard instrument available in many laboratories. Thus, ESR promises to be a convenient technique for qualitycontrol monitoring of the products of DOE nuclear waste vitrification installations.

\section{An Iron-Free Model HLW Glass}

More recently, group-C samples were examined in detail [13]. These samples consisted of small sawed prisms of simplified model $\mathrm{HLW}$ glass composition CSG (in mol \%: $59.3 \quad \mathrm{SiO}_{2}-7.3 \mathrm{Al}_{2} \mathrm{O}_{3}-7.7 \mathrm{~B}_{2} \mathrm{O}_{3}$ $18.8 \mathrm{Na}_{2} \mathrm{O}-6.8 \mathrm{CaO}$ ) developed at Lawrence Livermore Laboratory. ESR spectra of these samples were recorded before and after irradiation and after each of a sequence of 10-minute postirradiation anneals to elevated temperatures. As described in [13], the most numerous paramagnetic states in the unannealed samples following $\gamma$ irradiation were found to be boron-oxygen trapped-hole centers and $\mathrm{Ti}^{3+}$ centers resulting from electron trapping on impurity $\mathrm{Ti}^{4+}$ ions (see Fig. 4(a)). ESR spectra of the same classes of color centers in were recorded by other workers [23] in the course of investigating similar iron-free boroaluminosilicate glasses irradiated by $2.5 \mathrm{MeV}$ electrons to simulate damage by $\beta$ decays of immobilized radio nuclides.

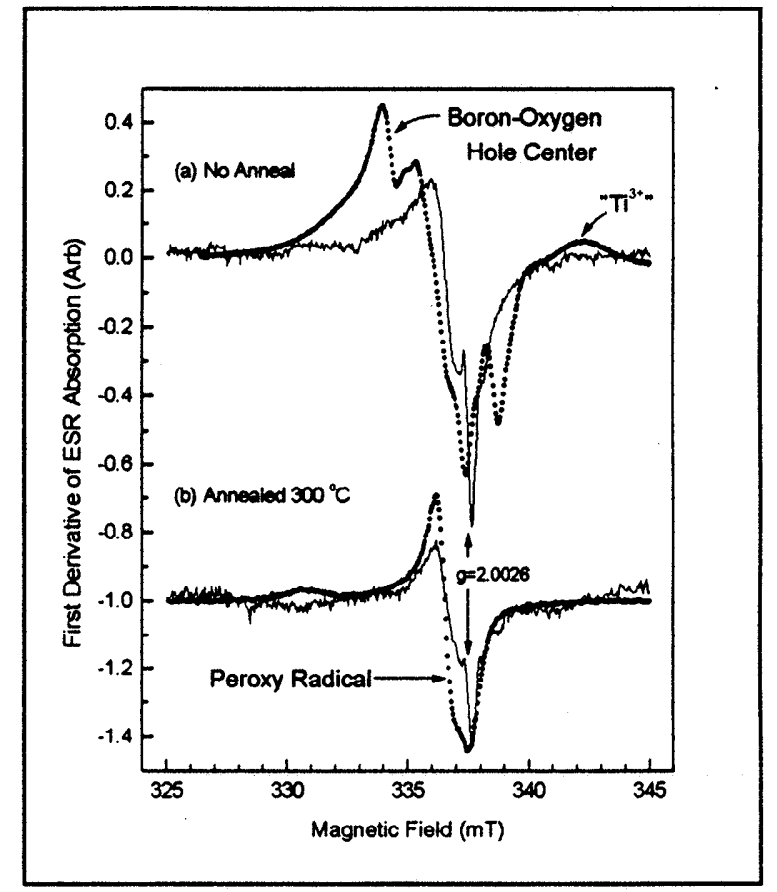

Figure 4. ESR spectra of iron-free HLW glass simulant CSG following $\gamma$ irradiation (dotted curves) and $160-\mathrm{keV}$ $\mathrm{He}^{+}$implantation (thin continuous curves): (a) before and (b) after 10-min anneals to $300^{\circ} \mathrm{C}$.

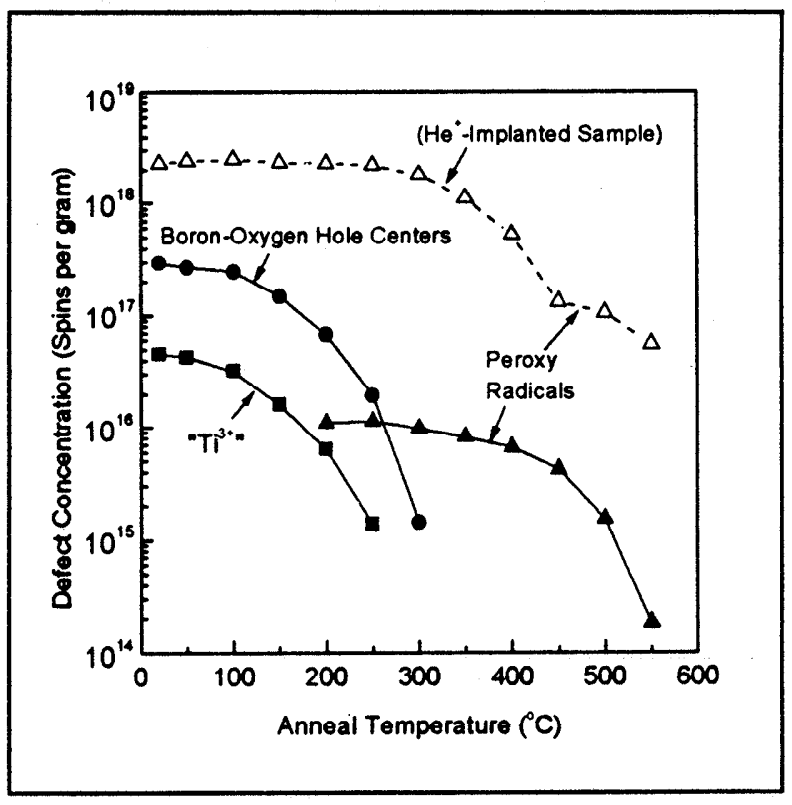

Figure 5. ESR isochronal anneal data for defect centers induced in iron-free HLW glass simulant CSG. Solid symbols: $\gamma$ irradiated. Open triangles: $\mathrm{He}^{+}$implanted. 
In the present work, $\mathrm{He}^{+}$implantation was employed to simulate the effects of $\alpha$ particles. In the latter case, the only observed paramagnetic species were peroxy radicals(PORs), which are $\mathrm{O}_{2}^{-}$ions bonded into the glass network (see Fig. 4(b)). Annealing the $\gamma$-irradiated samples above $300{ }^{\circ} \mathrm{C}$ caused recombination of the trapped electrons and holes, revealing an underlying POR spectrum which annealed in stages at $\sim 400$ and $550^{\circ} \mathrm{C}$ (Fig. 5, solid symbols). Similar isochronal annealing curves were recorded for PORs in the $\mathrm{He}^{+}$-implanted sample (Fig. 5 , open triangles). Figure 6 illustrates the different ESR spectral natures of POR spectra recorded after the 300 and $450{ }^{\circ} \mathrm{C}$ anneals. Successful computer simulations of the spectra of Fig. 6 (dotted curves) constrained by the Kanzig-Cohen formalism for the spin Hamiltonian parameters of $\mathrm{O}_{2}{ }^{-}$molecular ions in solid hosts [24] constitute strong evidence that these spectra are correctly attributed to PORs. A simulation of the POR component in the ion-implanted glass is shown in Fig. 7(a). For reference, the spectrum of unbonded $\mathrm{O}_{2}^{-}$ions in a $\gamma$-irradiated $44 \mathrm{~K}_{2} \mathrm{O}-66 \mathrm{SiO}_{2}$ glass [25], together with its simulation, are presented in Fig. 7(b). All spectral simulations of Figs. 6 and 7 were accomplished using the same parameterization of the Kanzig-Cohen $g$-value theory except for differing distributions of $g_{3}$ values (Fig. 8). Normalized to the amount of ionizing energy deposited per unit volume, the initial POR concentration in the $\mathrm{He}^{+}$-implanted sample was $\sim 100$ times that in the $\gamma$-irradiated sample. It is thus evident that the PORs induced by $\mathrm{He}^{+}$ implantation result predominately from displacements of oxygens in elastic collision cascades.

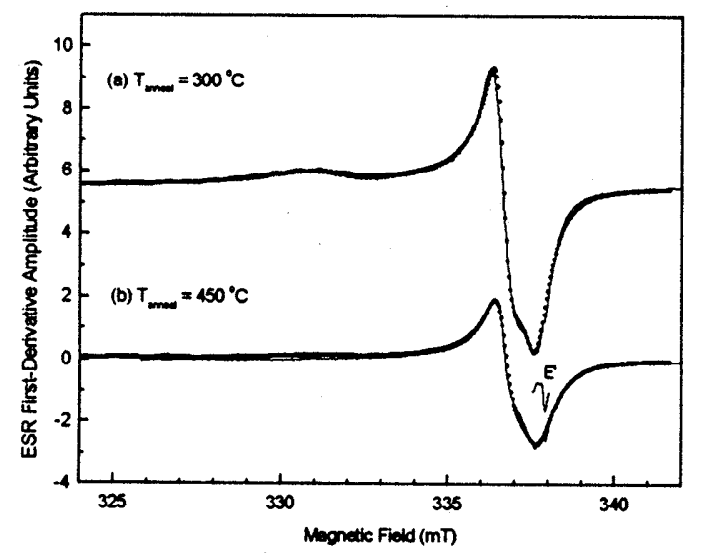

Figure 6. ESR spectra of iron-free borosilicate HLW glass CSG following $\gamma$ irradiation and annealing at (a) 300 and (b) $450{ }^{\circ} \mathrm{C}$. Dotted curves are computer simulations constrained by Känzig-Cohen $g$-value theory.

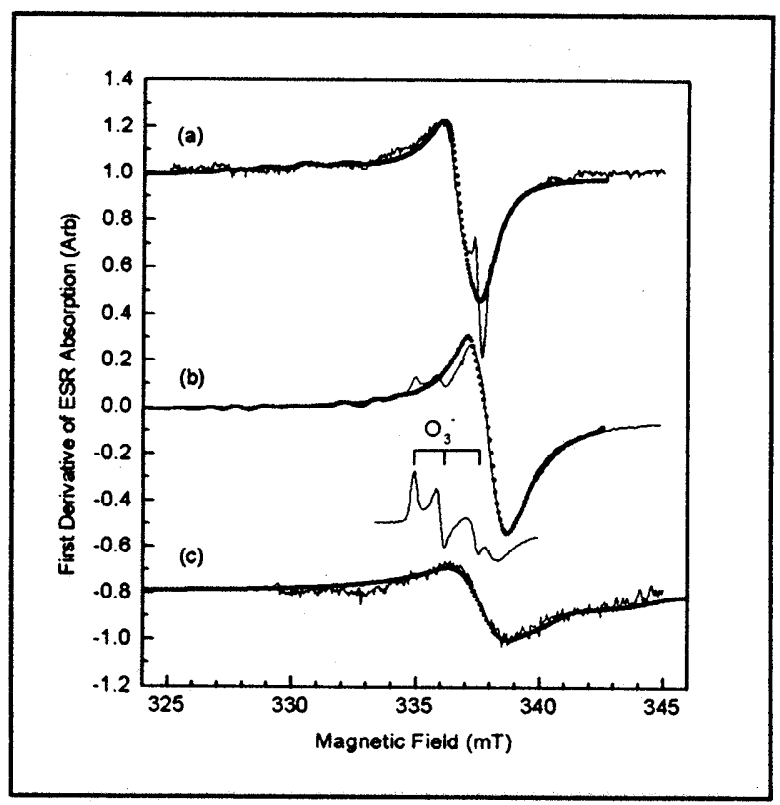

Figure 7. ESR spectra of (a) $\mathrm{He}^{+}$-implanted CSG glass, (b) a $\gamma$ irradiated $44 \mathrm{~K}_{2} \mathrm{O}-66 \mathrm{SiO}_{2}$ glass displaying spectra of $\mathrm{O}_{2}^{-}$and $\mathrm{O}_{3}^{-}$molecular ions, and (c) a 65-million-yearold tektite glass. Dotted curves are computer simulations constrained by Känzig-Cohen g-value theory [24].

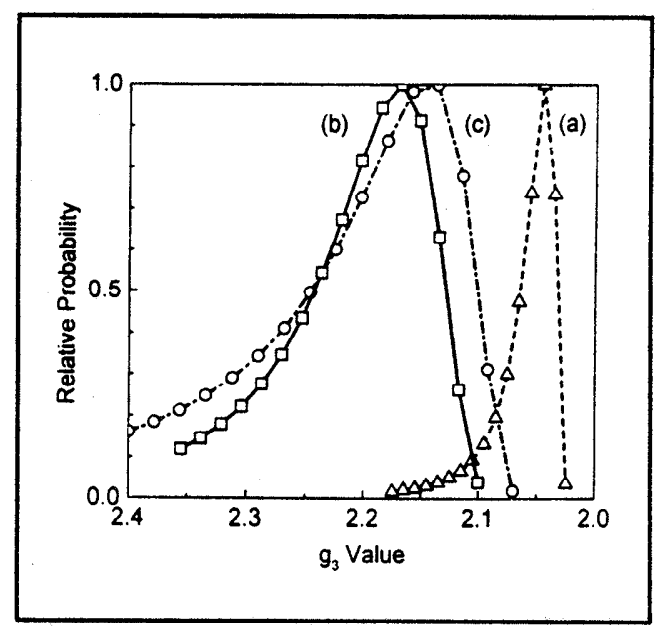

Figure 8. $g_{3}$-value distributions used in the respective lineshape simulations of Fig. 7.

The absence of trapped electrons and holes in the implanted samples has been ascribed to annealing during irradiation associated with the fraction of the implantation energy deposited as heat [13]. One of the fundamental defects to be expected in HLW glasses containing radionuclides undergoing $\alpha$ decay is therefore the POR [13]. 
In Fig. 4 a sharp ESR line can be noted centered at $g=2.0026$. Similar lines have been reported before in many oxide glass systems subjected to ion implantation (see literature cited in [13]) and have been diversely attributed as being related to oxygen, sodium, or carbon. Since model glass CSG contains a relatively large amount of sodium oxide and there is a concern for the possibility of sodium metal colloid formation under irradiation (as in the case for the alkali halides $[6,7])$, the temperature dependence of the linewidth was recorded to look for telltale signs of discontinuous changes at the melting point of sodium, $370.5 \mathrm{~K}$. The results are shown as the open symbols in Fig. 9, in juxtaposition with ESR data (solid circles) for sodium colloids in $\mathrm{NaN}_{3}$ [26]. While the initial run (squares) appeared to show an inflection near $370 \mathrm{~K}$, this result was not repeated on two subsequent runs. This observation, coupled with the wrong $g$ value $(2.0026$ vis-à-vis 2.0017 for sodium metal in sodium azide), led to rejection of the sodium colloid hypothesis. Since the strength of the $g=2.0026$ signal could be reduced by cleaning a dark surface coating from the implanted surfaces, this resonance was attributed to carbon pitch inadvertently resulting from hydrocarbons present in the vacuum system during implantation. This model is also supported by the fact that the carbon pitch used commonly used as an ESR intensity standard has a $\mathrm{g}$ value of 2.0028 .

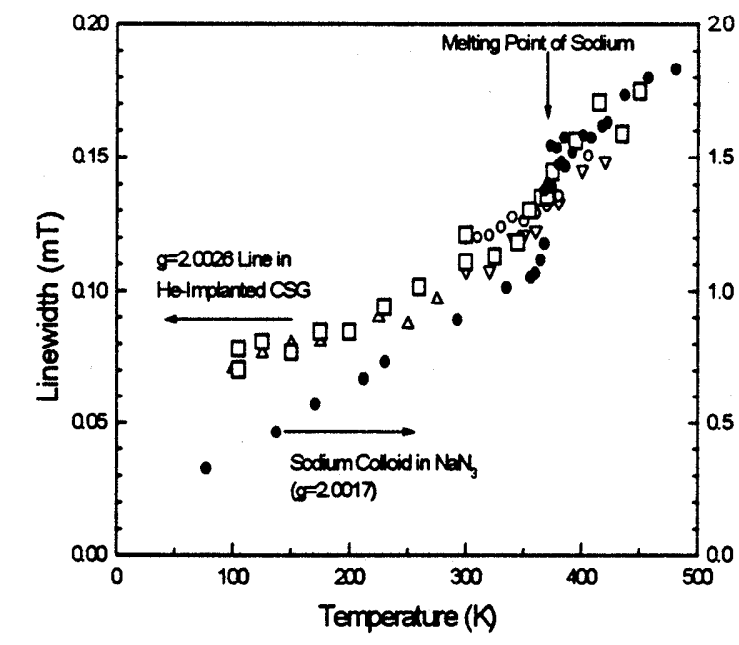

Figure 9. Temperature dependence of the ESR linewidth of the sharp line at $\mathrm{g}=2.0026$ recorded for model glass CSG after $\mathrm{He}^{+}$implantation (open symbols) with comparison to literature data [26] for the linewidth of the conduction-electron resonance of sodium metal colloids in sodium azide (filled circles).

\section{Geological Glasses}

Two samples of 65-million-year-old tektite glasses were investigated, each containing $\sim 5.3 \mathrm{wt} \%$ iron oxide. One of these, shown by ESR to contain $\sim 4.5$ times less $\mathrm{Fe}^{3+}$ than the other, displayed a narrow ESR signal which, as per the computer simulation of Fig. 7(d), might be considered as due to $\mathrm{O}_{2}^{-}$ions induced by $\alpha$ decays of contained radionuclides ${ }^{238} \mathrm{U}$ and ${ }^{232} \mathrm{Th}$ in amounts $\sim 1-10 \mathrm{ppm}$ ). The absence of this signal in the high $\mathrm{Fe}^{3+}$ glass was interpreted in [13] as an indication that redox may influence the amounts of induced $\mathrm{O}_{2}$.

However, more recent studies of $\gamma$-irradiated oxidized and reduced high-iron HLW glass simulants (NBS2 and NBS3, respectively; see below) showed no evidence of $\mathrm{O}_{2}^{-}$formation in either case. Neither did a 17-year-old oxidized high-iron glass containing 1.0 wt\% ${ }^{238} \mathrm{Pu}$ (DRG-P; see below) which should have experienced $\sim 4 \times 10^{6}$ times more $\alpha$ decays. Thus, the spectrum of Fig. 7(c) is perhaps better ascribed to other sources. Based on strong spectral similarity, this ESR signal could arise from aluminum-oxygen hole centers [27] and PORs induced by ${ }^{238} \mathrm{U}$ and ${ }^{232} \mathrm{Th}$ decays in quartz or silica glass co-present in the tektite sample.

Table 2. PNNL model HLW glass compositions.

\begin{tabular}{|c|c|c|c|c|c|c|c|}
\hline \multirow[t]{2}{*}{ Oxide } & \multicolumn{7}{|c|}{ Glass Composition (wt\%) } \\
\hline & DRG-P* & ARM1 & $\mathrm{MCCl}$ & NBSI & NBS2 & NBS3 & F43 \\
\hline $\mathrm{SiO}_{2}$ & 50.6 & 46.5 & 40.33 & 64.62 & 61.39 & 61.64 & \\
\hline $\mathrm{B}_{2} \mathrm{O}_{3}$ & 7.0 & 11.3 & 8.65 & 18.72 & 17.78 & 17.86 & \\
\hline $\mathrm{Al}_{2} \mathrm{O}_{3}$ & 6.0 & 5.59 & 0.84 & & & & \\
\hline $\mathrm{P}_{2} \mathrm{O}_{5}$ & & & 0.56 & & & & 55.0 \\
\hline $\mathrm{Na}_{2} \mathrm{O}$ & 9.1 & 9.67 & 11.6 & 16.67 & 15.83 & 15.9 & 13.3 \\
\hline $\mathrm{Li}_{2} \mathrm{O}$ & 4.9 & 5.08 & & & & & \\
\hline $\mathrm{Cs}_{2} \mathrm{O}$ & 0.5 & 1.16 & 1.21 & & & & \\
\hline $\mathrm{CaO}$ & 2.0 & 2.23 & 2.29 & & & & \\
\hline $\mathrm{Fe}_{2} \mathrm{O}_{3}$ & 10.0 & & 9.0 & & 4.99 & & 31.7 \\
\hline $\mathrm{FeO}$ & & & & & & 4.61 & \\
\hline $\mathrm{MgO}$ & 0.7 & & 0.18 & & & & \\
\hline $\mathrm{NiO}$ & 2.0 & & 0.25 & & & & \\
\hline $\mathrm{ZnO}$ & & 1.5 & 4.8 & & & & \\
\hline $\mathrm{SrO}$ & 0.5 & 0.45 & 0.49 & & & & \\
\hline $\mathrm{BaO}$ & & & 0.62 & & & & \\
\hline $\mathrm{Cr}_{2} \mathrm{O}_{3}$ & & & 0.5 & & & & \\
\hline $\mathrm{Ln}_{2} \mathrm{O}_{3}$ & & 7.5 & 6.6 & & & & \\
\hline $\mathrm{ZrO}_{2}$ & & 1.8 & 2.33 & & & & \\
\hline $\mathrm{MnO}_{2}$ & 3.0 & & 0.06 & & & & \\
\hline $\mathrm{TiO}_{2}$ & & 3.2 & 2.9 & & & & \\
\hline $\mathrm{MoO}_{3}$ & & 1.7 & 2.2 & & & & \\
\hline $\mathrm{PuO}_{2}$ & 1.0 & & & & & & \\
\hline $\mathrm{U}_{3} \mathrm{O}_{8}$ & 3.0 & & & & & & \\
\hline
\end{tabular}

"The ratio ${ }^{238} \mathrm{Pu}:{ }^{239} \mathrm{Pu}$ was varied in this glass series. 
Model HLW Glass Simulants from PNNL

The model HLW glass samples of Table 2 [28] were irradiated as part a broader study on a suite of glasses under an EMSP project ("Radiation Effects in Nuclear Waste Materials") at Pacific Northwest National Laboratory, and the present analyses were performed as part of a collaborative effort between the two projects. ESR spectra were run for a set of samples which had been $\gamma$ irradiated to a dose of 150 MGy at temperatures of $35,100,150$. In contrast to the samples of Table 1, which were powders, those of Table 2 were delivered as polished platelets $1 \mathrm{~mm}$ thick to facilitate optical and Raman studies at PNNL.

Glass NBS1 is the simplest borosilicate composition studied, comprising $66.7 \mathrm{SiO}_{2}-16.7 \mathrm{~B}_{2} \mathrm{O}_{3}$ $16.7 \mathrm{Na}_{2} \mathrm{O}$ in mole \%. Boron-oxygen hole centers (BOHCs) were observed in the irradiated NBS1 glasses, although the spectrum was the so-called "5-line" BOHC variant, rather than the "4-line" variant observed for glass CSG (Fig. 4(a))-a likely consequence of the 2.4times-lower $\mathrm{Na} / \mathrm{B}$ ratio in the former vis-à-vis the latter (see, e.g., [16]). The induced $\mathrm{BOHC}$ concentration in the NBS1 samples decreased with increasing irradiation temperature in a manner paralleling the isochronal anneal behavior of BOHCs induced in glass CSG at room temperature (Fig. 5). As in the case of CSG, some electrons were trapped on impurity titanium ions NBS1. However, unlike the isochronal anneal curve for $\mathrm{Ti}^{3+}$ in CSG (Fig. 5), the concentration of $\mathrm{Ti}^{3+}$ in NBS1 increased by a factor of 3 when the irradiation temperature was raised from 35 to $150^{\circ} \mathrm{C}$. It appeared that there is a POR signal overlapping that of the BOHCs.

ARM1 is another iron-free boro-aluminosilicate HLW glass simulant, but one of greater complexity than either NBS1 or CSG. Given that its composition includes $3.2 \mathrm{wt} \% \mathrm{TiO}_{2}$, it is not surprising that $\mathrm{Ti}^{3+}$ is observed as a radiation-induced color center. The number density of this center decreases by a factor of $\sim 2$ on increasing the irradiation temperature from 35 to $200{ }^{\circ} \mathrm{C}$. In addition, a strong POR spectrum is recorded whose strength is effectively independent of irradiation temperature up to $200^{\circ} \mathrm{C}$.

The remaining glasses of Table 2 all contain substantial amounts of iron oxide and, as in the case of the DWPF glass, none of these iron-rich boro-aluminosilicate compositions exhibited any $\gamma$-rayinduced color centers of any type. Clearly then, the presence of iron oxides in amounts $\geq 5 \mathrm{wt} \%$ acts to suppress formation of $\mathrm{BOHCs}$, PORs, and $\mathrm{Ti}^{3+}$ centers. Moreover, this suppression effect was observed equally in the otherwise-equivalent oxidized and reduced glasses NBS2 and NBS3, respectively. While Morssbauer spectroscopy is the preferred means of determining the precise redox states, the measured intensity of the ESR signal at $\mathrm{g}=\mathbf{4} .3$ suggests that the ratio $\left[\mathrm{Fe}^{3+}\right] /[\mathrm{Fe}]_{\text {total }}$ is $\sim 100$ times higher in NBS2 than NBS3. In principal, simultaneous suppression of both electron and hole trapping requires that a radiation protection agent be present in more than one valence state [29].

Finally, high-iron phosphate glass F43 of Table 2 (which differs from a glass of the same designation in Table 1 by the addition of $\mathrm{Na}_{2} \mathrm{O}$ ) exhibited a strong $\mathrm{X}$ resonance (similar to that of Fig. 1(a)), the intensity of which was unaffected by $\gamma$ irradiation. Moreover, as in the case of all high-iron boro-aluminosilicate glasses, but in contrast to the case of SRTC iron-phosphate glass $\mathrm{PO}_{4}-3$ (see above), no radiation-induced color centers were observed. The fact that the studied sample of the PNNL F43 glass was monolithic, whereas the $\mathrm{PO}_{4}-3$ glass was in powder form, is added support for the proposition that the ESR observed $\mathrm{O}_{2}{ }^{-}$ ions in the irradiated $\mathrm{PO}_{4}-3$ sample may have been the result of the radiation-stimulated reaction of atmospheric $\mathrm{O}_{2}$ with the high-surface area sample. While this hypothesis should be tested further, the preponderant evidence is that $\gamma$ irradiation has no ESRmeasurable effect on silicate or phosphate glasses containing $\sim 5 \mathrm{wt} \%$ or more iron oxides.

\section{${ }^{238}$ Pu-Containing Glasses}

On 20 July 1999, three model HLW glasses of chemical composition DRG-P* (Table 2) and isotopic compositions given in Table 3 [28] were shipped from Pacific Northwest National Laboratory to the Principal Investigator at NRL. These glasses were fabricated 17 years ago, leading to the respective internal radiation doses listed in Table 3. The DRG-P3 glass, containing the highest amount of ${ }^{238} \mathrm{Pu}$ (half life 87.7 years), emulates the combined effects of 5.2-MeV $\alpha$-particle and $86 \mathrm{keV} \alpha$-recoil damage which would accumulate in an actual ${ }^{239} \mathrm{Pu}$-containing glass after 4,700 years of storage.

Table 3. Isotopic compositions and accumulated internal doses as of 27 July 1999 in defense reference glasses containing 1.0 $w t \% \mathrm{PuO}_{2}$ with three selected replacements of ${ }^{239} \mathrm{Pu}$ by ${ }^{238} \mathrm{Pu}$.

\begin{tabular}{lccccc}
\hline Sample & $\begin{array}{c}\text { Amount } \\
{ }^{238} \mathrm{PuO}_{2}\end{array}$ & \multicolumn{3}{l}{ Dose } \\
\cline { 3 - 5 } & $(\mathrm{wt} \%)$ & $(\alpha$ decays/g) & $(\mathrm{Gy})$ & $(\mathrm{dpa})$ \\
\hline DRG-P1 & 0.0 & $9.0 \times 10^{15}$ & $7.9 \times 10^{6}$ & 0.0007 \\
DRG-P2 & 0.1 & $2.2 \times 10^{17}$ & $1.9 \times 10^{8}$ & 0.016 \\
DRG-P3 & 0.9 & $2.0 \times 10^{18}$ & $1.7 \times 10^{9}$ & 0.145
\end{tabular}




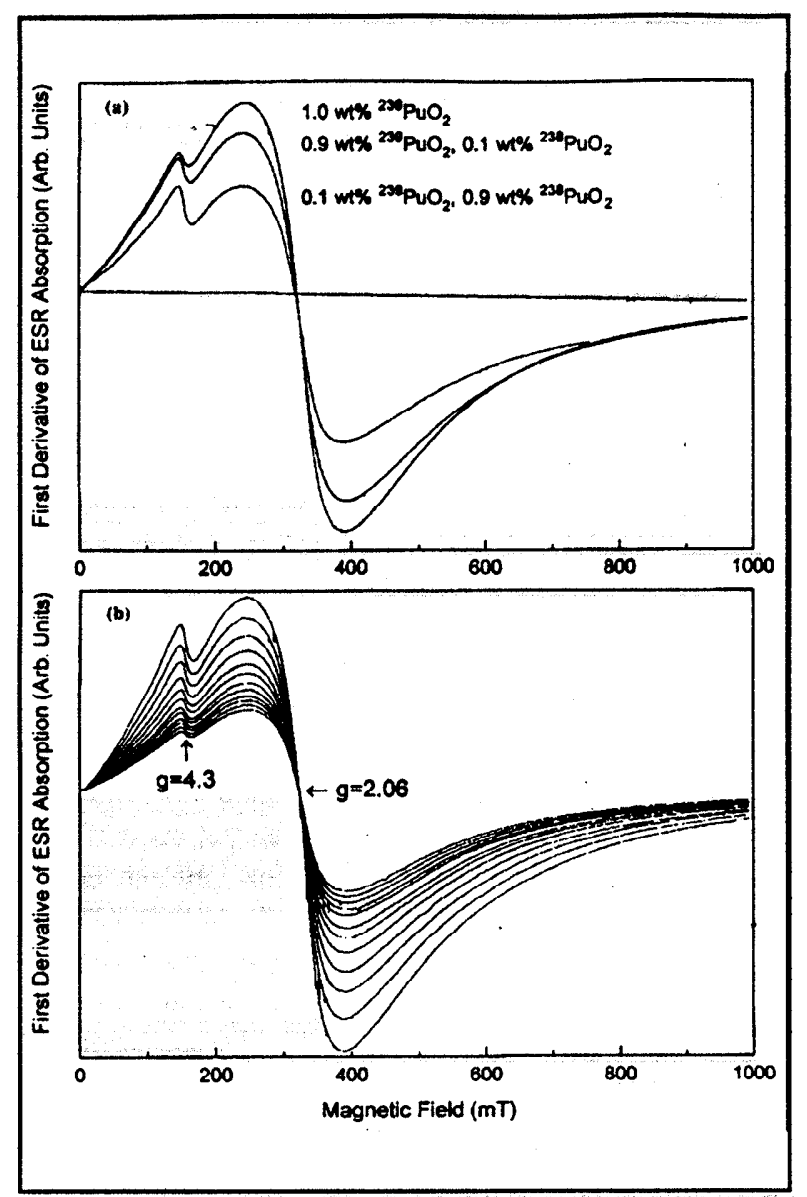

Figure 10. ESR spectra of plutonium-containing glasses DRG-P* recorded 17 years after their fabrication at PNNL: (a) Spectra of all three glasses at room temperature for identical conditions of [spectrometer gain $x$ sample mass]; the most intense spectrum is due to DRG-P1 and the least intense to DRG-P3. (b) Spectra of DRG-P1 recorded at $20^{\circ}-\mathrm{K}$ intervals from $100 \mathrm{~K}$ (strongest) to $320 \mathrm{~K}$ (weakest).

It can be seen in Fig. 10 that the ESR spectra of all of the DRG-P* glasses consist of a strong broad component near $g=2.06$ and a weaker component near $g=4.3$. Based on chemical composition, melting conditions, EXAFS data [30], an ESR lore [16, 31], each of these signals should arise from some form of $\mathrm{Fe}^{3+}$. In fact, the overall measured intensity of the ESR signal assuming $S=5 / 2$ states (as for $\mathrm{Fe}^{3+}$ ) converted to mass units of $\mathrm{Fe}_{2} \mathrm{O}_{3}$ was $0.088 \mathrm{~g} / \mathrm{g}$ vis-àvis the batched composition of $0.10 \mathrm{~g} / \mathrm{g}$. The $g=4.3$ feature is the well-known signature of isolated paramagnetic $\mathrm{Fe}^{3+}$ ions in glasses $[16,31]$. The $g=2.0$ signal is also familiar as arising from $\mathrm{Fe}^{3+}$ but its nature is less clearly understood. Depending on situation, the $g=2.0$ line has been attributed to antiferromagnetic clusters of $\mathrm{Fe}^{3+}$ ions $[30,31]$ and/or to fine-particle ferrites precipitated in the glass $[17,32]$.

The ESR spectra of Fig. 10(a), recorded at room temperature under identical conditions of spectrometer gain $x$ sample mass, reveal notable decreases in the amplitude of the broad spectrum centered near $g=2.06$ and corresponding increases in the amplitudes of the feature centered at $g=4.3$ as a function of increasing ${ }^{238} \mathrm{Pu}$ fraction. Thus, the iron ion sites responsible for the $g=2$ signal appear to be increasingly destroyed by the increasing $\alpha$-decay doses listed from top to bottom in Table 3, while concomitantly the isolated $\mathrm{Fe}^{3+}$ sites associated with the $g=4.3$ feature are increased. The temperature dependence of the $g=2.0$ line (Fig. 10(b)) is not inconsistent with its arising from ferrites particles $\sim 3-10 \mathrm{~nm}$ [17]. The amount of ferrites required in this model would account for $3 \%$ of the total iron in the sample. In this event, the remaining $97 \%$ of the iron would account for the $g=4.3$ signal. However, this model is contradicted by the fact that ${ }^{238} \mathrm{Pu} \alpha$ decays in the DRG-P3 glass have reduced to $g=2.0$ line by a factor $\sim 2$ while increasing the $g=4.3$ line by about the same factor (see Fig. 11). It is logically impossible that transformation of $3 \%$ of the total iron from ferrimagnetic particles into paramagnetic states would double the ESR signal associated with the paramagnetic states of the remaining $97 \%$. The $g=2.0$ signal is therefore ascribed to $\mathrm{Fe}^{3+}$ in small clusters which behave paramagnetically.

The temperature dependence of Fig. 10(b) must be interpreted as indicating that some of the $\mathrm{Fe}^{3+}$ in the $g=2.0$ sites is reversibly converted to $\mathrm{Fe}^{3+}$ in $g=4.3$ sites upon cooling. One way of explaining this is to model the $g=2.0$ sites as $\mathrm{Fe}^{3+}-\mathrm{Fe}^{2+}$ close pairs between which electrons undergo thermally activated hopping.

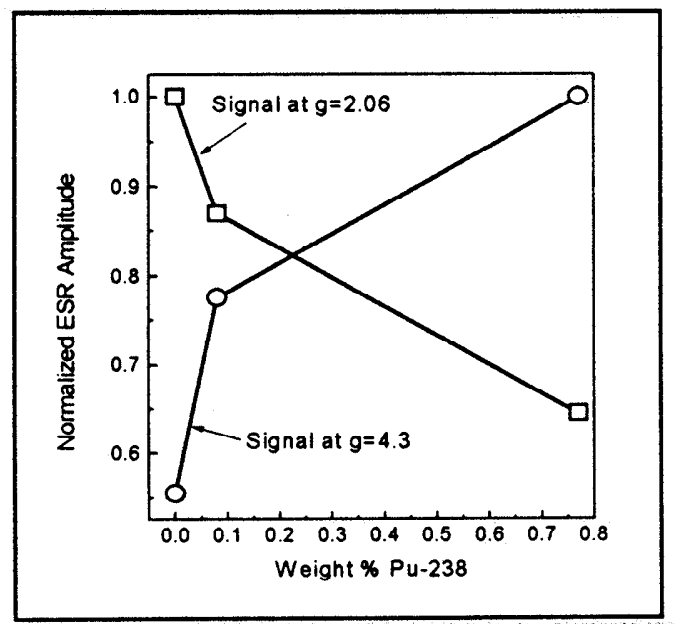

Figure 11. Normalized amplitudes of the ESR signals at $g=2.06$ and $g=4.3$ in Fig. 10 plotted as a function of the weight $\%{ }^{238} \mathrm{Pu}$ in the respective samples. 
The interpretation of the results of Figs. 10(a) and 11, therefore, is that $\alpha$ decays of ${ }^{238} \mathrm{Pu}$ in the $0.9 \%{ }_{-}^{238} \mathrm{PuO}_{2}$ glass have destroyed about $50 \%$ of the " $\mathrm{Fe}^{3+}$ clusters" initially present, converting them to isolated $\mathrm{Fe}^{3+}$ ions. The initial presence of such clusters is consistent with microscopic observation of swirling light and dark striae in thin sections of the as-prepared glasses [28]. It is further noted that the number of rearranged atoms in the thermal spikes associated with the $\alpha$ particles and $\alpha$-recoil ions can easily be 3 times the number of atoms displaced by inelastic collisions [28]. Since the fraction of the total atoms which are ballistically displaced in the $0.9 \%{ }_{-}^{238} \mathrm{PuO}_{2}$ glass is 0.145 (Table 3), the homogenization of $50 \%$ of the clusters inferred from Fig. 11 is entirely reasonable.

There was no ESR evidence of color center formation in any of the Pu-containing glasses despite the large internal doses listed in Table 3. This can be attributed to the suppressive effects of the high iron content. It is unclear, however, whether or not any interstitial oxygen molecules were produced. While ESR-observable PORs and superoxide ions are chemical intermediates in reactions which yield ${ }^{\cdot} \mathrm{O}_{2}$ [11], the non-observation of these species is no guarantee that oxygen molecules are not produced directly. It is therefore recommended that searches for interstitial $\mathrm{O}_{2}$ in these glasses be conducted by Raman and infrared photoluminescence spectroscopies $[32,33]$. In any event, it is conceivable that the radiation induced homogenization elucidated here could render these glasses more resistant to chemical corrosion than they are in their unirradiated condition.

\section{Post Script: A Possible Lesson from Geological Glasses}

A surprising recent discovery is the fact that several geological materials exhibit ESR spectra virtually identical to those of Fig. 10 in line shape, $g$ values, and the striking temperature dependence (the $g=2.0$ feature partially converts to $g=4.3$ signal at lower temperatures). Two of these materials are 65-millionyear-old clays [17] and a third is a putatively-35million-year-old quartz silt [34]. In all cases, the ESR signal strengths are suggestive that these ancient materials contain as much as $10 \%$ high-iron glassperhaps similar to the silicate HLW glasses of the present study. If glass is really present, it has not been previously recognized as such. However, identification of glassy particles by petrographic microscopy is difficult for particle sizes smaller than $\sim 63 \mu \mathrm{m}$ [35].

If in fact there exist geologic glasses in particle sizes of the order of a few tens of microns which have survived ground water attack for 65 million years, then their isolation and study might lead to the development of HLW vitrification media which will continue to immobilize their radioactive waste loadings long after ground water has invaded their geologic repositories.

\section{TECHNICAL SUMMARY}

A variety of HLW glass simulants exposed to various forms of irradiation were examined by electron spin resonance (ESR) techniques to look for early signs of radiation-induced chemical decomposition.

High-iron phosphate glasses. The ESR spectra of both the irradiated and unirradiated high-iron phosphate glasses exhibited unusual properties which stimulated in-depth structural studies in collaboration with the University of Missouri-Rolla (project 55110), Toyo University (Japan) and the University of Reading (UK). A new structural model for these glasses appears to be emerging [22] which may assist in tailoring compositions for HLW vitrification. The present ESR studies have revealed no evidence of radiolytic decomposition, although nothing can yet be said about possible radiolytic production of interstitial $\mathrm{O}_{2}$ molecules. In any event, glasses in this category appear to possess great chemical durability and should be especially suitable for vitrification of highphosphorus tank wastes at the Hanford reservation [18].

Iron-free boro-aluminosilicate glasses. The present study [13] and others [23] have shown that ionizing radiation in the form of $1.3-\mathrm{MeV} \gamma$ rays or 2.5-MeV electrons produce copious numbers of boronoxygen trapped-hole centers and $\mathrm{Ti}^{3+}$ trapped-electron centers, in addition to smaller numbers of peroxy radicals (a precursor of oxygen molecules), in iron-free boro-aluminosilicate glasses of various compositions. By contrast, helium-ion implantation of comparable ionizing dose, did not yield measurable numbers of trapped carrier centers; rather, it generated two orders of magnitude more PORs. The additional PORs may be due to the effects of inelastic collisions or they may result from the higher excitation density in the ion tracks vis-à-vis other forms of ionizing radiation (e.g., $\gamma$ rays) which deposit energy more uniformly. In either event, it is likely that the heat energy co-delivered by the He ions was responsible for the non-observation of trapped carrier centers (which in the $\gamma$-irradiated samples could be annealed out at $\left.300^{\circ} \mathrm{C}[13]\right)$. It is concluded that oxygen bubbles are likely to form in iron-free boro-aluminosilicate glasses, particularly those with high alkali contents.

High-iron borosilicate glasses. Five borosilicate and boro-aluminosilicate HLW glass simulants containing 5 or more wt\% iron oxide exhibited no ESR evidence of color centers or iron valence changes for $\gamma$ ray doses up to $150 \mathrm{MGy}$. Apparently, large amounts of iron oxide present in either silicate or phosphate 
glasses have a tenancy to suppress color center formation, similar to the case of cerium ions in optical glasses [29]. However, it is not possible to discount the formation of interstitial oxygen molecules on the basis of ESR measurements, which cannot detect $\mathrm{O}_{2}$ directly. Therefore, it is recommended that Raman and/or photoluminescence methods [32, 33] be employed to make this determination.

${ }^{238} \mathrm{Pu}$-containing glasses. Defense Reference Glass (DRG) HLW compositions containing up to $0.9 \mathrm{wt} \%$ ${ }^{238} \mathrm{PuO}_{2}$ fabricated at Pacific Northwest Laboratories 17 years ago have suffered a calculated 0.145 displacements per atom due to $\alpha$-decay-related collisional processes and perhaps an additional 0.3 displacements per atom due to concomitant radiolysis and melting in thermal spikes (project 54672 [28]). This is the equivalent of storing the same amount of ${ }^{239} \mathrm{Pu}$ in vitrified form for 4,700 years. Still, no color center formation was noted by ESR. One reason for this may be thermal bleaching of trapped-carrier centers due to the thermal spiking, and another reason may be the already noted suppressive effect of large iron oxide contents (in this case $10.0 \mathrm{wt} \%$ ). Again, the formation of interstitial oxygen molecules cannot be ruled out and this possibility must be checked by other methods. However, a significant effect was recorded which did not occur in high-iron boro-aluminosilicate glasses which were $\gamma$-irradiated. Namely, large quantitative changes in the character of the dominant ESR signals due to $\mathrm{Fe}^{3+}$ were observed in the ${ }^{238} \mathrm{Pu}$ glasses only. It was concluded that this effect was due to the destruction of heterogeneities in the glass microstructure, tending to convert $\mathrm{Fe}^{3+}$ pairs and clusters into uniformly dispersed isolated ions. In principal, this effect could cause the chemical durability of actual HLW glasses to improve with time.

Lessons from geology. Millimeter-sized tektite glasses created in the Chicxulub (Mexico) impact 65 million years ago have survived exposures to sea and ground water until the present time (e.g., [17]). Further studies of these and other ancient glasses may enable vitrification technologies capable of immobilizing high level nuclear wastes for comparable times.

\section{RELEVANCE, IMPACT AND TECHNOLOGY TRANSFER}

In the United States alone there are 100 million gallons of high-level nuclear wastes (HLWs) in various chemical forms awaiting eventual disposal in geologic repositories. But since the approval of the Defense Waste Processing Facility at the Savannah River Reservation nearly two decades ago, there had been a virtual moratorium on research or development of vitreous waste forms until the advent of the Environmental Management and Sciences Program. The present project should contribute substantially to the now greatly expanded body of knowledge concerning the long-term viability of vitrification media against not only attack by ground water but also decomposition induced by the decays of the immobilized high-level wastes and excess plutonium.

In particular, the present project has highlighted the possible role of high iron oxide contents in ameliorating radiolytic decomposition of vitreous waste forms and has pointed out some recent experimental methods which are capable of confirming or disproving this inference. It has united several research groups around the world in performing new fundamental studies of the structures and radiation resistances of a family of high-iron phosphate glasses with many remarkable properties. Such glasses seem ideal for vitrification of certain high-phosphate tank wastes at Hanford. The present work has included the first observation of a rather profound homogenization effect in 17-year-old glasses prepared at PNNL (project 54672) containing up to 0.9 weight $\%{ }^{238} \mathrm{PuO}_{2}$. This glass had suffered $\alpha$-decay effects equivalent to 4,700 years storage of ${ }^{239} \mathrm{Pu}$ prior to measurement. Finally, the present project has called to the attention of the nuclear waste community to the existence of natural glasses as old as 65 million years. If such glasses could be fabricated as high-level waste vitrification media, they might promise to outlive their geologic repositories.

This project was a basic research effort. No new technologies were developed nor was it expected that there would be. Rather, the fundamental knowledge gained here may provide additional confidence in existing HLW vitrification technologies and/or avenues of trouble shooting them, as well as a kernel from which new technologies may spring.

\section{PROJECT PRODUCTIVITY}

The project achieved all of its proposed goals, as well as some unanticipated discoveries.

\section{PERSONNEL SUPPORTED}

The only personnel supported under this program were the Principal Investigator, David L. Griscom, and the Co-Investigator, Celia I. Merzbacher. 


\section{PUBLICATIONS}

Two papers on radiation effects in $H L W$ glasses:

"On the structure and radiation chemistry of iron phosphate glasses: New insights from electron spin resonance, Mössbauer, and evolved-gas mass spectroscopy," D.L. Griscom, C.I. Merzbacher, N.E. Bibler, H. Imagawa, S. Uchiyama, A. Namiki, G.K. Marasinghe, M. Mesko, and M. Karabulut, Nucl. Inst. \& Methods B 141 (1998) 600-615.

"Electron Spin Resonance Studies of Defect Centers Induced in a High-Level Nuclear Waste Glass Simulant by Gamma-Irradiation and Ion-Implantation," D.L. Griscom, C.I. Merzbacher, R.A. Weeks, R.A. Zuhr, J. Non-Cryst. Solids 258 (1999) 34-47.

\section{One paper in the area of geological glasses:}

"Electron spin resonance of 65-million-year-old glasses and rocks from the Cretaceous-Tertiary boundary," D.L. Griscom, V. Beltrán-López, C.I. Merzbacher, and E. Bolden, Selected papers from the 18th International Congress on Glass, San Francisco, CA, July 10-15, 1988; J. Non-Cryst. Solids 253 (1999) 1-22.

\section{INTERACTIONS}

In addition to authoring two major publications (see above), the Principal Investigator was an invited panelist at the DOE-sponsored "Research Needs and Opportunities in Radiation Chemistry Workshop" in Chesterton, IN, 19-22 April 1988 and a member of the Subpanel on Waste Forms. He was a contributor to the EMSP Science Program Workshop in Rosemont, IL, 27-30 July 1998 where he presented a poster paper. He was also an invited speaker on the subject of HLW glasses at the meeting of the American Chemical Society, Anaheim, 21-25 March 1999 and an invited participant in the topical workshop "Structure and Evolution of Glasses under Irradiation" at Commissariat a L'Energie Atomique, Saclay, France, 17-18 September 1998. Finally, the PI presented a talk on the structure of high-iron phosphate glasses at the Ninth International Conference on Radiation Effects in Insulators, Knoxville, TN, 14-19 September 1997.

This project has benefitted from collaborations with N.E. Bibler (Savannah River Technology Center), G.K. Marasinghe (University of Missouri-Rolla), H. Imagawa (Toyo University, Japan), W.J. Weber (Pacific Northwest National Laboratory), A.C. Wright (University of Reading, UK), and B. Boizot (Commissariat a L'Energie Atomique, Saclay, France).

\section{PATENTS}

No patents have resulted from this study.

\section{FUTURE WORK}

No continuation of the present project is anticipated. However, the Principal Investigator hopes to extend his efforts to discover and characterize previously unrecognized classes of geologic glasses which are chemically durable for tens of millions of years.

\section{LITERATURE CITED}

[1] W.J. Weber, R.C. Ewing, C.A. Angell, G.W. Amold, A.N. Cormack, J.M. Delaye, D.L. Griscom, L.W. Hobbs, A. Navrotsky, D.L. Price, A.M. Stoneham, and M.C. Weinberg, J. Mater. Res. 12 (1997) 1946.

[2] J.C. Cunnane and J.M. Allison, in Scientific Basis for Nuclear Waste Management XVII, A. Barkatt and R.A. Van Konynenburg, Eds., Materials Research Society, Pittsburgh, Pa, 1994, p. 3.

[3] K.D. Crowley, Physics Today 50 (1997) 32.

[4] R.C. Ewing, J. Nucl. Mater. 190 (1992) 7.

[5] C.M. Jantzen, J. Am. Ceram. Soc. 75 (1992) 2433.

[6] L.W. Hobbs, J. Physique 37 (1976) 3.

[7] P.W. Levy, J.M. Loman, and J.A. Kierstead, Nucl. Inst. \& Methods B1 (1984) 549.

[8] D.I. Vainstein, C. Altena, and H.W. den Hartog, Materials Science Forum 239-241 (1997) 607.

[9] H.W. den Hartog and D.I. Vainstein, Materials Science Forum 239-241 (1997) 611

[10] J.F. DeNatale and D.G. Howitt, Nụcl. Inst. \& Methods B1 (1984) 489.

[11] N.-G. Vannerberg, Prog. Inorg. Chem. 4 (1962) 125.

[12] D.L. Griscom, C.I. Merzbacher, N.E. Bibler, H. Imagawa, S. Uchiyama, A. Namiki, G.K. Marasinghe, M. Mesko, and M. Karabulut, Nucl. Inst. \& Methods B141 (1998) 600 .

[13] D.L. Griscom, C.I. Merzbacher, R.A. Weeks, and R.A. Zuhr, J. Non-Cryst. Solids 258 (1999) 34-47.

[14] D.L Griscom, W.J. Weber, N. Hess (to be published).

[15] J.A. Weil, J.R. Bolton, and J.E. Wertz, Electron Paramagnetic Resonance: Elemental Theory and Applications, J. Wiley, New York, 1996, 575 pp.

[16] D.L. Griscom, in: Glass: Science and Technology Vol. $4 B$, D.R. Uhlmann and N.J. Kreidl, Eds., Academic Press, Boston, 1990, p. 151.

[17] D.L. Griscom, V. Beltrán-López, C.I. Merzbacher, and E. Bolden, J. Non-Cryst. Solids 253 (1999) 1-22.

[18] D.E. Day et al., Final report to PNNL, Contract No. 276822-A-F1, Dec., 1995.

[19] T. Egami, O.A. Sacli, A.W. Simpson, A.L. Terry, and F.A. Wedgwood, in A morphous Magnetism, H.O. Hooper and A.M. deGraaf, Eds, Plenum, New York, 1973, p. 27.

[20] F A. Wedgwood and A.C. Wright, J. Non-Cryst. Solids (1976) 95. 
[21] G.K. Marasinghe, M. Karabulut, C.S. Ray, M.G. Shumsky, W.B. Yelon, C.H. Booth, P.G. Allen, and D.K. Shuth, J. Non-Cryst. Solids 222 (1997) 144.

[22] A.C. Wright et al. (experimental reports to Institut Laue-Langevin, Grenoble, and to be published).

[23] B. Boizot, G. Petite, D. Ghaleb, and G. Calas, Nucl. Inst. \& Methods B141 (1998) 580.

[24] T.G. Castner and W. Känzig, J. Phys. Chem. Solids 3 (1957) 178.

[25] R. Cases and D.L. Griscom, Nuc. Inst. \& Methods B1 (1984) 503.

[26] R.C. McMillan, G.J. King, B.S. Miller, and F.F. Carlson, J. Phys. Chem. Solids (1962) 1379.

[27] R. Schnadt and A. Răuber, Sol. State Commun. 9 (1971) 159.

[28] W.J. Weber, (PNNL, private communication).

[29] J. Stroud, J. Chem. Phys. 43 (1965) 2442.

[30] N. Hess, (PNNL, private communication).

[31] T. Castner, G.S. Newell, W.C. Holton, and C.P. Slichter, J. Chem. Phys. 32 (1960) 668.

[32] L. Skuja, B. Guttler, D. Scheil, and A.R. Silin, J. Appl. Phys. 83 (1998) 6106-10.

[33] L. Skuja, B. Guttler, D. Scheil, and A.R. Silin, Phys. Rev. B 58 (1998) 14296-304.

[34] D.L. Griscom and E. Bolden, EOS Vol. 80, no. 17; suppl. (1999) p. s211.

[35] B.P. Glass, (U. Delaware, private communication). 
